University of Nebraska - Lincoln

DigitalCommons@University of Nebraska - Lincoln

Management Department Faculty Publications

Management Department

Spring 2007

\title{
Diversity Training: Analysis of the Impact of Self-Efficacy
}

\author{
Gwendolyn Combs \\ University of Nebraska - Lincoln, gcombs2@unl.edu \\ Fred Luthans \\ University of Nebraska-Lincoln, fluthans1@unl.edu
}

Follow this and additional works at: https://digitalcommons.unl.edu/managementfacpub

Part of the Management Sciences and Quantitative Methods Commons

Combs, Gwendolyn and Luthans, Fred, "Diversity Training: Analysis of the Impact of Self-Efficacy" (2007). Management Department Faculty Publications. 28.

https://digitalcommons.unl.edu/managementfacpub/28

This Article is brought to you for free and open access by the Management Department at DigitalCommons@University of Nebraska - Lincoln. It has been accepted for inclusion in Management Department Faculty Publications by an authorized administrator of DigitalCommons@University of Nebraska - Lincoln. 


\title{
Diversity Training: Analysis of the Impact of Self-Efficacy
}

\author{
Gwendolyn M. Combs and Fred Luthans
}

University of Nebraska-Lincoln

\begin{abstract}
Although the importance of diversity in organizations is widely recognized, diversity training is under attack. Drawing from self-efficacy theory and research, we developed a questionnaire to measure one's efficacy of successfully coping with widely recognized diversity initiatives. Then we conducted a study examining the effect of self-efficacy-based diversity training on the level of participant's measured diversity self-efficacy (DSE) and the possible mediation of this DSE on intentions to pursue positive diversity-related initiatives. The field experimental design showed that training incorporating efficacy components significantly increased trainees' $(N=276)$ measured DSE. Diversity training was also shown to be positively related to the trainees' stated levels of difficulty and magnitude in coping with diversity initiatives. Finally, the DSE was found to mediate training and intentions. Importantly, one-year follow-up data supported the impact of the intentions. The practical implications of these findings for HRD in general and diversity training in particular conclude this article.
\end{abstract}

Over the past few decades, U.S. organizations have attempted to respond to the value of diversity. Diversity can be a relative concept defined globally in terms of group and cultural dissimilarities (Bucher, 2000) or with regard to sociological categories of demography (Tsui \& Gutek, 1999). Our use of the term diversity refers to the primary immutable dimensions of individual and group differences of race, ethnicity, gender, ability, and age (Baytos, 1995). The focus on diversity in the workplace results from demographic shifts of racial and ethnic minorities, women, and older workers in the domestic workforce and from pressures of globalization (Wentling \& Palma-Ri-

The authors thank Bruce Avolio, University of Nebraska-Lincoln, and Alex Stajkovic, University of Wisconsin-Madison, for their helpful suggestions on the previous draft of this article. 
vas, 2000). Organizations face specific diversity-related challenges, including group member differences in beliefs, perceptions, and experiences (Thomas \& Proudford, 2000) and inter- and intragroup biases and stereotypes (Dass \& Parker, 1996).

Global organizations must operate in sync with the issue of fairness and equity arising from diversity challenges in many countries-for example, gender equity in Sweden and France, racial inequality in South Africa, religious differences in Ireland, and caste and religious inequalities in India (Haq, 2004). These issues are becoming increasingly challenging as organizations attempt to sustain viability and enhance profitability in markets that are more and more complex due to employee and constituent diversity (Combs, Nadkarni, \& Combs, 2005). Effectively managing diversity affects organizational viability and profitability through more creative decision making, reduced diversity-related conflict, improved cross-cultural understanding, and more functional interpretation of pluralistic differences (Bell, 2006; Connerley \& Pedersen, 2005; Cox, 2000; Cox \& Beale, 1997; Dass \& Parker, 1996). To meet these global and domestic challenges, organizations are embracing a number of workplace initiatives.

The most widely used and pragmatic of organizational workplace diversity initiatives is diversity training (Roberson, Kulik, \& Pepper, 2003). Organizations have commonly used this training as an efficient method to instill knowledge and direct employee actions to promote positive work climates. Galvin (2003) in Training's 2003 Annual Industry Report showed that 79 percent of organizations surveyed provide diversity training for their employees. The effectiveness of such training rests in the participants' ability to transfer diversity training back to the job.

Diversity training seeks to promote a positive diversity climate by influencing actual and intended interactions of employees with diverse coworkers and clients (Wentling \& Palma-Rivas, 2000). This process encompasses the impact of diversity training on the cognitive disposition of trainees as they return to the job. However, in spite of these goals, very little attention is devoted to assessing the outcomes and impact of diversity training in terms of the skills provided to trainees and, more important, their belief and confidence (that is, their efficacy) that what they learn in training can be transferred to the work setting (Holladay, Knight, Paige, \& Quiñones, 2003). We propose that diversity training outcomes and transfer may be positively influenced by the trainee's diversity self-efficacy (DSE), which we define as the perception and belief (confidence) that one can marshal the necessary motivation, cognitive resources, and courses of action to change behaviors and successfully attain desired diversity goals and initiatives in the workplace.

Diversity self-efficacy is analogous to similar applications of self-efficacy such as computer self-efficacy (Gist, Schwoerer, \& Rosen, 1989) and sales selfefficacy (Barling \& Beattie, 1983) found in the workplace self-efficacy literature. DSE is similar to other forms of efficacy in that all reference confidence 
in individual skills to perform within a task domain. Task specificity is the focus that rarely requires interpretation of or convergence with strongly held beliefs and values. However, DSE may be affected more by manifested strong and entrenched beliefs and values embedded in cognitive processes. That is, the psychosocial forces that influence diversity behaviors, such as personal biases and learned stereotypes toward particular groups, may not be as easily identified or acknowledged by individuals in a training environment (Stockdale \& Cao, 2004). Prejudices and biases toward others are more emotionally charged perceptions that require in-depth analysis and control of affective responses (Cox \& Beale, 1997). Barriers to full inclusion in the workplace operate at individual, group, and organizational levels and may be more subtle than overt in nature (Cox, 2000). Perceptions of skill deficits in sales training may be rational and concrete, whereas perceptions of skill deficits in the diversity domain may tend to be more irrational and abstract (Bell, 2006).

The purpose of this study is to examine diversity training that emphasizes Bandura's self-efficacy principles (1997) and the relationship of this diversity training to the intentions of participants to engage back on the job in initiatives to promote diversity subsequent to the training. This study assesses the effectiveness of diversity training through its impact on diversity self-efficacy and trainees' intentions to engage in positive diversity initiates. A favorable return on investment in diversity training is important to human resource development (HRD) as a field of study with a major focus on training and development in the enhancement of human capital (Goldstein \& Ford, 2002). In addition, this study should be of particular interest to HRD practitioners charged with creating and improving workplace environments and employee productivity.

\section{Background and Hypotheses}

In addition to factors such as the design and content of the training program, trainee cognitive processes play a critical role in accomplishing learning, retention, and transfer back to the job (Goldstein \& Ford, 2002; Hanover \& Cellar, 1998). In particular, we suggest that the psychological construct of self-efficacy, although recognized in the general training literature (Mager, 1992), is relevant to but overlooked in diversity training. Bandura (1986) defines self-efficacy as "people's judgments of their capabilities to organize and execute courses of action required to attain designated types of performances" (p. 391). Self-efficacy has been examined in a number of workplace domains over the years, including the application to training (Gist, 1989; Schwoerer, May, Hollensbe, \& Mencl, 2005). Stajkovic and Luthans (1998a), through meta-analysis, found a strong correlation between self-efficacy and work-related performance. In spite of these positive findings, no studies were found that empirically examined the effectiveness of diversity training that incorporates self-efficacy components on intentions to engage in positive diversity initiatives subsequent to training. While attention is given to the expected outcomes of diversity training, such 
as worker harmony, enhanced worker productivity, and improved organizational performance (Wentling \& Palma-Riva, 1998), little attention has been focused on specific cognitive processes that may bear on trainee success with diversity goals and initiatives subsequent to training.

Diversity and Diversity Training. Organizational diversity concerns have had a great impact on strategies and practices that affect the acquisition and deployment of human resources and the dynamics of operational processes (Thomas \& Proudford, 2000). Despite the progress over the past several decades, issues of diversity in the workplace continue to pose challenges and problems in today's organizations:

- Interactions among various demographic groups continue to result in conflicts (Stockdale \& Cao, 2004).

- Organizational policies and procedures that facilitate a more diverse workforce continue to generate opposition among traditional employees (Kidder, Lankau, Chrobot-Mason, Mollica, \& Friedman, 2005; Plantena, 2004).

- Perceptions of preferential treatment continue to criticize diversity programs (Combs \& Nadkarni, 2005; Kravitz \& Klineberg, 2000).

- Lower job involvement and satisfaction for minorities and women continue to exist (Roberson \& Block, 2001).

- Covert, subtle, and aversive discrimination continue to stigmatize groups (Brief et al., 2002).

Organizations that foster a positive diversity climate are those that select, develop, and promote talent regardless of origin; ensure that pluralistic perspectives are welcomed and heard; demonstrate improved understanding of diverse markets and clients; foster participation in organizational decision making by diverse groups; emphasize the creation of an organizational culture that shuns stereotypes, biases, and prejudices that hinder the individual development and the achievement of organizational goals; and formulate strategic organizational goals that link to successfully managing diversity (Bell, 2006; Cox, 2000; Cox \& Beale, 1997; Kidder et al., 2005; Wiethoff, 2004; Wentling \& Palma-Rivas, 1998, 2000).

Diversity initiatives including diversity training have evolved from a primary focus on legal and regulatory compliance to recognition of the performance impact and the bottom line (Richard, 2000). As the president of Diversity Training Group, Mauricio Valasquez has stated, "You are not looking at diversity training because 'it is the right thing to do.' You are looking at diversity training because your employees and customers demand it. Corporate diversity efforts are about money, business and the bottom line" (Barbian, 2003, p. 45). I agree with this change. Organizations such as Xerox and Motorola employ diversity education programs to enhance both domestic and global employee interactions (Combs et al., 2005). However, the effectiveness of diversity training programs can be difficult to determine and remains a major challenge (Davidson, 1999). 
The Interface of Self-Efficacy and Diversity Training. High-profile discrimination lawsuits have led to questions about the place of diversity training in eliminating discriminatory practices and actions (Hemphill \& Haines, 1997). The concern is whether the outcomes of diversity training justify the organizational resources spent on design and implementation (Davidson, 1999). Responses to diversity training are mixed at best, with some calling for its elimination (Hemphill \& Haines, 1997) and others suggesting greater integration of diversity training (Wentling \& Palma-Rivas, 2000). Cox (2000) emphasizes the need to refocus diversity training to address the cognitive processes that improve skill to operate effectively in diverse environments.

Throughout the HRD and training literatures, diversity training has been examined in terms of content and design (Davidson, 1999; Holladay et al., 2003), organizational context factors (Hanover \& Cellar, 1998), planned behavior and behavioral control (Wiethoff, 2004), organizational justification (Kidder et al., 2005), and attitudes toward training and diversity initiatives (De Meuse \& Hostager, 2001). While these arguments sometimes address issues of diversity training content, they almost always ignore ways to assess the cognitive and self-regulatory attributes of trainees (for example, their selfefficacy and confidence) as a measure of diversity training effectiveness (Roberson et al., 2003).

We propose that self-efficacy is a cognitive, self-regulating attribute of trainees that may be applicable to assessing the effectiveness of diversity training. There is limited research on diversity training in general (Holladay et al., 2003), and, especially, an examination of its success or failure has not been adequately assessed (Wiethoff, 2004). Self-efficacy is generally seen as important in attaining training objectives and transfer back to the job and has considerable research support (Colquitt, LePine, \& Noe, 2000; Schwoerer et al., 2005; Wood \& Bandura, 1989). However, to date, we have not found research that has focused on diversity training incorporating self-efficacy. If self-efficacy beliefs can influence training effectiveness and, subsequently, improved performance back on the job in other domains, then we propose that self-efficacy also may have positive implications for diversity training effectiveness.

Self-Efficacy, Intentions, and Behavior Relationship. A major focus of organizational diversity initiatives is to have an impact on employee thinking and attitudes such that interpersonal interactions and workplace behaviors will reflect positive diversity outcomes. Diversity training particularly seeks to have an impact on behaviors and outcomes subsequent to training. However, unlike other subjects of training, such as computer or sales training, the opportunity to execute actual behaviors and cognitive processes taught in diversity training may not be exhibited immediately after training. Thus, the most proximal measure of training impact is the trainee's intentions to perform following training. The relationship of self-efficacy to intentions is explicitly recognized by Bandura (1997) as follows: "Beliefs in personal efficacy 
affect behavior both directly and by influence on intentions" (p. 284). Thus, the focus on intentions in this study is the influence of self-efficacy beliefs on intentions.

Intentions have been considered among the best predictors of future behavior and have been commonly used in research as a proxy for and indicator of actual future behaviors (Hom, Griffeth, \& Gaertner, 2000; Kirschembaum \& Weisberg, 2002). In particular, Betz and colleagues (Betz \& Luzzo, 1996; Betz \& Voyten, 1997) have examined the relationship of self-efficacy beliefs to intentions regarding various components of educational and vocational behavior. These studies show support for self-efficacy as a predictor of career decision-making intentions. Specifically, Betz and Voyten (1997) in a laboratory study of 350 students examined distinctions between efficacy beliefs and outcome expectations on career decision making. They found that career self-efficacy had a positive significant relationship to career decisionmaking intentions. Similarly, Zhao, Seibert, and Hills (2005) found that entrepreneurial self-efficacy was positively related to entrepreneurial intentions to open a business. This study also found that entrepreneurial self-efficacy mediated the relationship between perceptions of formal learning in entrepreneurial courses and entrepreneurial intentions. In the health sciences literature, there are a number of studies where efficacy beliefs have a positive relationship to intentions to pursue health-related actions (see Rodgers \& Brawley, 1996). Finally, self-efficacy has been positively related to academic achievement intentions (Manstead \& van Eekelen, 1998) and also math interest and math choice intentions (Waller, 2006).

Based on this considerable body of knowledge of the relationship between various types of efficacy and intentions, we formulate the following hypothesis for our study:

HYPOTHESIS 1. There will be a positive relationship between diversity self-efficacy and intentions to undertake a greater number and more challenging diversity behaviors and initiatives in the trainee's real-world (nontraining context) environment.

Transfer of Diversity Training Back to the Job. Although this study does not center on training transfer, transfer of learning clearly has an impact on perceptions of diversity training ineffectiveness (Wentling \& Palma-Rivas, 2000). Most declarations of the ineffectiveness of diversity training emanate from the perceived lack of improved work environments and continued employee involvement in non-diversity-friendly behaviors following diversity training. The common backlash to diversity training may be mainly the result of transfer climate issues (Kidder et al., 2005). The training literature in general establishes that both environmental (Ford \& Weissbein, 1997; Tracey, Tannenbum, \& Kavanagh, 1995) and trainee personal characteristics (Colquitt et al., 2000) are critical transfer factors. Holton, Bates, and Ruona (2000) argue that the identification of the transfer system that might promote or inhibit 
transfer of learning from a particular training domain must be assessed. For example, two of their lists of eleven training-specific factors are trainee reactions to positive and negative experiences and motivation to transfer learning. These two factors are examples of trainee characteristics that may have an important impact on diversity training effectiveness.

Trainee characteristics and attitudes are relatively neglected in the analysis and recommendations for the effectiveness of training in general (Colquitt et al., 2000; Ford \& Weissbein, 1997; see also Smith-Jentsch, Salas, \& Brannick, 2001). Personal attributes are important to both the motivation to learn and to transfer learning back on the job. In addition, measures of the motivation to transfer training back to the job are incomplete without assessment of the confidence level to use learned skills (Colquitt et al., 2000; Mager, 1992). Although Bandura (1997) does make a distinction between confidence and efficacy, other efficacy theorists use the terms interchangeably (Maddux, 2002), and the term confidence is commonly used when applied to human resource management (Kanter, 2004). Thus, we will use efficacy and confidence interchangeably.

The diversity trainee needs the confidence (self-efficacy) to mobilize the motivation and cognitive resources to learn and transfer skills related to diversity initiatives and goals back on the job (Mager, 1992). This confidence allows the trainee to value and promote diversity goals and initiatives (Holladay et al., 2003). Although there are obviously societal attitudes and values and organizational culture components that are beyond the control of individual trainees (Holton et al., 2000), the element that is under their control is how they think about diversity, how they behave toward it back on the job (Plantenga, 2004), and the climate they as individuals can create for true equal opportunity in the workplace - that is, what we are calling the trainee's diversity self-efficacy.

We proposed that self-efficacy beliefs may become the sought-after bridge for individual managers and employees to apply positive diversity initiatives in the workplace. Bandura (1997) and others (Maddux, 2002; Stajkovic \& Luthans, 1998a, 1998b) have conceptually and empirically demonstrated that the strength of one's self-efficacy is directly related to one's willingness to take on a task, the effort to accomplish the task, and the persistence when problems are encountered. This high-efficacy profile leads us to propose that trainees high in diversity self-efficacy are confident that they can personally make the necessary adjustments (Roberson et al., 2003) to create a difference back on the job-for example, proximal factors such as convincing others in their department through words and deeds the important contribution that diversity can make toward higher performance (Bandura, 2000; Cox, 2000). Also, those with high diversity self-efficacy will persist in their efforts in spite of distal factors such as societal, organizational, or peer problems in supporting diversity initiatives (Bell, 2006). As Baytos (1995) has noted, for diversity training to be effective, participants must perceive themselves as being accountable for their actions, motivated to choose to perform, willing to exert the necessary effort, and persist over a long period of time. In other words, diversity 
trainees must have the necessary self-efficacy in order to successfully accomplish the diversity training objectives back on the job (De Meuse \& Hostager, 2001). This considerable body of theory and research leads to our second hypothesis for the study:

HYPOTHESIS 2. Trainees high in diversity self-efficacy will experience significantly increased posttraining intentions to undertake a greater number and more challenging diversity behaviors and initiatives in the trainee's real-world (nontraining context) environment.

Self-Efficacy as a Mediator Between Diversity Training and Intentions. Bandura (2000) suggests that personal perceptions of self-efficacy strongly influence choice behavior and form the basis of judgments of ability to perform successfully in a given task domain. For example, Eden and Aviram (1993) found that self-efficacy significantly enhanced job search activities of unemployed workers. Although no literature was found that specifically addressed self-efficacy in the diversity domain, research supporting the application of self-efficacy generally in the workplace (Bandura, 2000; Luthans, 2002a, 2002b; Stajkovic \& Luthans, 1998b), in specific task performance domains (Eden \& Zuk, 1995; Gist, Stevens, \& Bavetta, 1991; Schwoerer et al., 2005; Stajkovic \& Luthans, 1998a), and in relation to its association with intentions (Betz \& Voyten, 1997; Zhao et al., 2005), it follows that diversity training that incorporates Bandura's $(1986,1997)$ sources of self-efficacy (enactive mastery, modeling, persuasion, and arousal) should enhance and develop diversity self-efficacy perceptions.

Colquitt and colleagues (2000) in their meta analysis on training motivation propose that self-efficacy played a role as both an antecedent and outcome of training motivation. Specifically, they propose that self-efficacy has a strong association with motivation to learn and training transfer and a moderate relationship with declarative knowledge, skill acquisition, and job performance. As a motivational and skills acquisition component of diversity training, self-efficacy may serve two complementary roles. First, by attending to self-efficacy principles in training, skills to effectively handle challenging diversity situations may be attained. Second, such training may enhance trainees' beliefs in their own capabilities to apply existing skills effectively and affect the number of performance initiatives that trainees may attempt (Stajkovic \& Luthans, 1998a). For example, Machin and Fogarty (2003) in their study of computer skills training depict self-efficacy as a critical training outcome with a direct influence on transfer implementation intentions.

Studies of self-efficacy tend to point to either a moderator (Eden \& Aviram, 1993) or mediator role (Gist et al., 1991) of self-efficacy on intentions or behavior. Mager (1992) urges HRD practitioners and researchers not to underestimate the link of self-efficacy to performance. He postulates that skills without positive self-efficacy perceptions will not result in task performance. 
Gist and colleagues (1991) suggest that the level of perceived self-efficacy affects motivation and behavior through its mediation of knowledge or skill and action. Based on these relationships, we formulate our third hypothesis for the study:

HYPOTHESIS 3. Diversity self-efficacy will mediate the influence of training on both the difficulty and the number of diversity-related intentions selected.

\section{Method}

To test the study hypotheses, a field experimental design was used. Preand postanalyses were conducted on the training or treatment group. Onetime control group measures were obtained and used in the between-group analysis of postmeasures. This design strategy is commonly used in studies investigating learning and transfer of learning (Keppel, 1991) and allowed the assessment of both within-subject and between-subjects sources of variance. Trainee self-efficacy and intentions were assessed pre- and posttreatment and again one year later. The follow-up data obtained through surveys distributed to experimental training participants and control group members approximately one year following the training are reported as post hoc descriptive analysis in aggregate form.

Participants. The convenience sample consisted of 276 participants from three organizations in the Midwest. These three organizations were a medium-sized manufacturing firm $(N=58)$, a medium-sized insurance company $(N=86)$, and a medium-sized government agency $(N=132)$. All three organizations had established equal employment opportunity policies but had not systematically provided formal diversity training for their employees. Since this study examined diversity, access to employees can be and usually is problematic (Ivancevich \& Gilbert, 2000). Therefore, openness of the organization to allow participation of their employees in an academic study of diversity was a major factor in the selection of these companies.

Study participants across these three organizations worked in a variety of positions: managers, secretaries, marketing specialists, accountants, information technology technicians, engineers, groundskeepers, sales representatives, maintenance technicians, and claims processors. There were 118 (43 percent) manager-supervisors and 154 (56 percent) nonmanagerial participants (4 did not respond to this questionnaire item) in the study. Of these, 57 percent were male, 43 percent were female, 93 percent were white, and 7 percent were racial/ethnic minorities. Participants averaged 20.3 years of total work experience, 50 percent were eighteen to forty-one years old, and 63 percent of the participants had some college or more. There were no significant differences among study participants in terms of gender, age, education, or total work experience. 
Procedures. The diversity training developed for this study consisted of a six-hour, one-day training program. In terms of selection, each organization provided three dates to sign up for participation in an "organizational seminar" (three different sets of dates for each organization). Based on business and travel schedules, individuals signed up for the seminar. To ensure participants from each organization were in both the experimental and control groups, employees for each organization were randomly assigned to either the experimental or control group. Specifically, we did not have the flexibility to move people around among the three days available in each organization for training (for example, some had to travel from other parts of the state to take the training). Therefore, within each organization, each sign-in sheet was given a number and randomly assigned to training or control groups. In addition, questionnaires measuring diversity self-efficacy and diversity intentions were developed and administered. In the control sessions, the participants $(N=86)$ filled out the developed diversity efficacy questionnaire, but the organizations did not allow for alternative training.

The on-site facilities were typically used for group-based training and accommodated individual and group exercises. All three facilities were comparable in size, ambiance, and general location. The same experienced and credentialed diversity trainer presented all training sessions. All participant organizations either had existing (but not necessarily operative) plans to increase diversity or were developing one at the time of the study.

Training Intervention. The study hypotheses suggest that raising participant diversity self-efficacy will have a positive impact on the effectiveness of diversity training in terms of trainee intentions. For diversity training to influence self-efficacy, training content should reflect guidelines designed to enhance diversity self-efficacy. Bandura's four components (1997) for influencing efficacy beliefs - enactive mastery, modeling, verbal/social persuasion, and psychological arousal-were used. These four sources of efficacy beliefs were addressed in the training session. For example, enactive mastery experiences were facilitated through the use of case scenarios, role plays, and group interactive exercises, where participants experienced success; relevant modeling incorporated video examples of appropriate versus inappropriate attitudes and actions with critiques and contingent rewards; verbal/social persuasion was facilitated through feedback and positive affirmation from the training facilitator; and psychological arousal centered on information on benefits of diversity, consequences of actions (favorable and unfavorable), and compliance issues. This focused training session built around these components was aimed at developing the trainees' diversity self-efficacy. That is, trainees would be more confident in their abilities to attain positive diversity goals and initiatives.

Diversity Efficacy Questionnaire Development. The diversity efficacy questionnaire (DEQ) was developed for this study in order to measure trainee diversity self-efficacy at pre- and posttraining and one year following the 
training. For this study, we followed Bandura's mandate that "an efficacy belief is not a decontextualized trait" (Bandura, 1997, p. 42) and thus developed a specific measurement of diversity self-efficacy. In other words, following Bandura's recommendation, we could not use a standardized general efficacy scale but needed to measure efficacy in this situation and this context of diversity.

Several levels of review and analysis facilitated the development of the eventual thirty-four items of the DEQ. First, studies that developed and designed measurement scales for the self-efficacy construct were reviewed (Barling \& Beattie, 1983; Eden \& Aviram, 1993; Gist et al., 1989; Sherer, Maddux, Mercandante, Prentice-Dunn, Jacobs, \& Rogers, 1982; Stajkovic \& Luthans, 1998a; Zimmerman \& Bandura, 1994). Second, the diversity management, diversity training, and general training literatures were examined for diversity program objectives, training methodologies, and behaviors important to diversity management (Cox, 2000; Cox \& Beale, 1997; Hanover \& Cellar, 1998; Hemphill \& Haines, 1997; Richard \& Johnson, 1999). Third, an expert panel of fourteen diversity and human resource development professionals was used to address face and content validities to ensure that the measurement instrument comprehensively represented items associated with confidence in diversity-related situations (Rosenthal \& Rosnow, 1991). The panel response rate was 79 percent, with agreement on thirty of the initial items. Follow-up with the panel resulted in agreement on all items and the addition of an item reflecting ability to challenge organizational policies and decisions that have an adverse impact on a positive diversity climate. This resulted in a thirtyfouritem questionnaire. To address potential anchoring influence in the DEQ, the thirty-four items were listed in random order.

To assess the dimensionality of the DEQ and examine the relationship and fit of the thirty-four items, two factor analyses were conducted: one on the posttraining data for the training group and another on a separate student sample. The principal components method with varimax rotation was used. For the postdata for the training group, one component accounted for 51 percent of variance (eigenvalue $=17.3$ ). The next component accounted for only 6.8 percent of variance. This information in conjunction with the scree plot supported a one-dimensional scale. One item of the scale relating to laws and regulations was dropped due to lack of fit in the one-factor loading and consistently low communality, resulting in a thirty-three-item scale for hypotheses testing. In interpreting the factor loadings, we used 4 as our minimum cutoff.

The factor structure of the DEQ was further tested using a sample of 185 students enrolled in organizational behavior classes. This sample consisted of 106 males and 79 females, with 90.3 percent being white and 9.7 percent racial/ethnic minorities. Factor analysis of the student sample replicated the analysis of study participants, indicating a single factor that accounted for 40 percent of variance (eigenvalue $=13.7$ ). Cronbach alpha reliability of the student sample was .95 . Gorsuch (1974) recommends that the number of sub- 
jects be at least five times the number of variables for a valid factor analysis. This analysis meets this minimum sample size of 170 . Corresponding components matrix representing factor loadings for the student sample used to validate the factor structure of the DEQ is presented in Table 1. In addition, Figure 1 in the appendix shows the scree plot of the factor extraction. In summary, this factor analysis evidence, using different samples, lends support to the use of the DEQ as a measure of a specific task in a given context (Stajkovic \& Luthans, 1998b), diversity self-efficacy, for this study.

An assessment of construct validity was obtained by comparisons of the DEQ with the Intolerance of Ambiguity (IA) Scale (Budner, 1962) and the Negative and Positive Affect (PANA) scales (Watson, Clark, \& Tellegen, 1988). These scales were administered at the same time as the DEQ and were chosen because they are conceptually related to the DEQ measure. For example, IA has been associated with ethnocentrism $\left(\mathrm{O}^{\prime} \mathrm{Connor}, 1952\right)$ and offers support for diversity programs (Chen \& Hooijberg, 2000), and affective state has been shown to influence employee actions toward desirable organizational behaviors (Williams \& Shiaw, 1999). To support convergent validity, it is expected that DEQ scores would correlate negatively with IA and negative affectivity and positively correlate with positive affectivity. As expected, measures of the DEQ correlated negatively with IA $(\mathrm{r}=-.30, p<.001)$; negatively with negative affect $(r=-.21, p<.001)$; and positively with positive affect $(r=.48, p<$ .001 ), thus contributing evidence to convergent and discriminate validity, that is, construct validity of the DEQ measure used in this study.

Diversity Intentions. Because of the organizations' perception of sensitivity and confidentiality of actual diversity performance by employees, we use intentions as a surrogate for actual behavior back on the job. We were able to directly assess the number and difficulty level of the trainees' intentions related to specific diversity behaviors and initiatives back on the job. Participants indicated on a confidential Institutional Review Board-approved basis the intentions they would pursue relating to their involvement in actions to value and positively promote diversity on the job.

All intention statements were rated for level of difficulty (easy, moderate, difficult), reflecting the average of ratings by the same diversity expert panel used to develop the DEQ and a group of laypersons. Laypersons were individuals who were not considered professionals working in the diversity arena. The trainees' open-ended, self-generated intentions (those not on the list) were also rated for difficulty on the same scale as the preset intentions.

One Year After the Experiment Assessment. Approximately one year following the training, 231 participants in the experiment (controls $=67$; experimental $=164$ ) received a questionnaire to obtain their personal perceptions of training effectiveness and to what level their intentions to promote a positive diversity climate were accomplished. Because forty-five of the confidential training enrollments could not be provided by the participating organizations, not all the original participants could be identified to receive follow-up 
Table 1. Validation Sample Factor Analysis Components Matrix for DEQ

\begin{tabular}{|c|c|c|c|c|c|c|c|}
\hline Variable & 1 & 2 & 3 & 4 & 5 & 6 & 7 \\
\hline SES1 & .613 & -.004 & .191 & .134 & -.299 & -.193 & -.208 \\
\hline SES2 & .612 & -.134 & .332 & -.003 & .006 & .162 & -.276 \\
\hline SES3 & .478 & .241 & .356 & .317 & -.073 & .002 & -.123 \\
\hline SES4 & .588 & .179 & .006 & .147 & -.219 & .338 & -.081 \\
\hline SES5 & .484 & .164 & .521 & .007 & .231 & -.190 & -.134 \\
\hline SES6 & .505 & -.105 & -.052 & .178 & .537 & .306 & .001 \\
\hline SES7 & .560 & -.142 & -.057 & .326 & .218 & .433 & -.094 \\
\hline SES8 & .615 & .211 & -.283 & .187 & .245 & .005 & -.041 \\
\hline SES9 & .615 & .171 & -.257 & .199 & .006 & .008 & -.012 \\
\hline SES10 & .562 & -.391 & -.022 & .211 & -.023 & -.087 & .004 \\
\hline SES11 & .716 & .277 & -.107 & -.063 & .179 & -.170 & -.163 \\
\hline SES12 & .622 & .208 & .271 & -.396 & .007 & .153 & -.018 \\
\hline SES13 & .711 & .391 & .001 & .004 & -.215 & .006 & -.063 \\
\hline SES14 & .608 & .343 & -.309 & -.350 & -.181 & .150 & .001 \\
\hline SES15 & .560 & .182 & .158 & .008 & .001 & -.295 & .166 \\
\hline SES16 & .645 & .323 & .173 & .205 & -.082 & .152 & -.093 \\
\hline SES17 & .671 & -.118 & -.021 & .007 & -.265 & .002 & -.385 \\
\hline SES18 & .688 & .400 & -.255 & -.123 & -.200 & .005 & -.047 \\
\hline SES19 & .713 & -.192 & .111 & -.058 & -.154 & -.053 & .183 \\
\hline SES20 & .627 & .187 & .124 & .256 & -.087 & .226 & .309 \\
\hline SES21 & .571 & .003 & .115 & .307 & -.078 & .173 & .345 \\
\hline SES22 & .672 & .345 & -.240 & -.120 & -.209 & .007 & .172 \\
\hline SES23 & .640 & -.038 & .354 & -.436 & .138 & .006 & .004 \\
\hline SES24 & .535 & -.272 & -.286 & -.200 & .278 & .004 & -.019 \\
\hline SES25 & .667 & -.385 & -.042 & .010 & -.034 & -.265 & .006 \\
\hline SES26 & .723 & -.260 & -.213 & -.033 & .002 & -.054 & -.159 \\
\hline SES27 & .726 & -.098 & -.229 & -.014 & .189 & -.157 & -.137 \\
\hline SES28 & .707 & .001 & .241 & -.378 & .107 & .114 & .003 \\
\hline SES29 & .720 & -.411 & -.074 & .002 & -.229 & -.004 & -.089 \\
\hline SES30 & .730 & -.319 & -.162 & .004 & -.294 & .006 & -.010 \\
\hline SES31 & .619 & -.407 & -.021 & -.098 & -.128 & .155 & -.023 \\
\hline SES32 & .692 & .133 & -.280 & -.171 & .234 & -.171 & .007 \\
\hline SES33 & .654 & -.083 & -.092 & .009 & .006 & -.289 & .442 \\
\hline SES34 & .602 & -.326 & .323 & -.236 & -.001 & .002 & .260 \\
\hline
\end{tabular}

Extraction method: principal component analysis. Alpha reliability: .95. 
requests. From the 231 questionnaires sent out, 132 responded (57 percent response rate; control, $N=34$; experimental $N=98$ ). Completed responses in the one-year follow-up represented 48 percent of the original study participants. The follow-up assessment required participants to again complete the DEQ, respond to specific questions on training effectiveness, and again assess their performance on the set of intentions statements.

Individual responses to the questionnaire as part of the training intervention were completely anonymous, preventing the one-year follow-up questionnaires from being matched with specific individuals in the initial experiment. Therefore, data and analysis are reported in aggregate form.

Measures. The DEQ measure used in training pre- and postassessments was numbered for data-matching purposes. Although it was not possible to associate specific participants to particular questionnaires, it was possible to pair pre- and postquestionnaires for analysis.

Diversity Self-Efficacy. The thirty-three-item DEQ was used to assess efficacy perceptions regarding diversity-related initiatives and behaviors on pre- and posttraining and the one-year follow-up. Examples of DEQ items include: "I can communicate effectively with people from different racial, ethnic and cultural backgrounds"; "I can manage my behaviors toward those who are different from me"; "I can analyze unique situations and recognize the diversity issues in them"; "I can acknowledge that people are sometimes treated inequitably based on actual and perceived differences"; and, "I can reinforce/encourage others' behaviors that offer a supportive diversity climate."

To score the DEQ, the recommended use of both self-efficacy magnitude and strength was assessed to formulate the measure of diversity self-efficacy (Bandura, 1986, 1997; Lee \& Bobko, 1994). Participants confidentially and anonymously responded either yes or no to each of the DEQ diversity behavior statements representing diversity self-efficacy magnitude. Confidence, or self-efficacy strength, was recorded on a scale of 0 percent (no confidence) to 100 percent (total confidence). Following the recommendation of Lee and Bobko (1994), the DSE score was the sum of the strength values (percentages of confidence) for all yes responses on self-efficacy magnitude. The Kaiser-Meyer-Olkin measure for sample adequacy was .91 for the pretraining and .96 for the posttraining. Cronbach alpha reliability was .95 , .97 , and .96 for pretraining, posttraining, and one-year follow-up samples, respectively.

Intentions. Participants were asked to indicate specific intentions by selection from the developed list of possible intentions and also open-ended specification of others. The list contained ten possible intentions, reflecting the most common themes of positive initiatives found in the diversity literature (for example, "I will facilitate the participation of my work group and/or organization in a community service project related to diversity" and "I will make a conscious effort to identify statements and actions of racism, sexism, 
discrimination, intolerance and harassment and will challenge them in an appropriate yet effective manner"). "Intention Difficulty" and "Number of Intentions" selected were the two measures used for the study. Cronbach alpha reliability pretraining, posttraining, and the one-year follow-up are .74, .76, and .77 , respectively.

For Intention Difficulty (INTDIF), each item on the intention inventory was rated on a 1 to 3 scale, with $1=$ easy, $2=$ moderate, and 3 =difficult. Trainees selected these intentions at pre- and posttraining and at the oneyear follow-up. Intention difficulty scores were a total of the difficulty ratings on the specific intentions selected. Number of Intentions Selected (INTSEL) reflects the summation of the items indicated by the trainees on the intention inventory. Pre- and posttraining and one-year follow-up measures were obtained.

Control Variables. Control variables were the organization and the trainees' age, gender, race/ethnicity, and total work experience. These variables were identified because they might affect participants' orientation to valuing diversity and the importance of undertaking positive diversity-related behaviors and initiatives. As Schwoerer and colleagues (2005) observed, there is little empirical evidence in general training studies that actively attend to these types of demographic variables. However, Cox and Nkomo (1991) in related research have found effects of race and gender. In addition, worker age and amount of time interacting in organizational contexts may influence perceptions of diversity training programs.

One-Year Follow-up Assessment. One year following the training interventions, a measure of the effectiveness of diversity training received was obtained through participant responses to seven questions measured on a scale of 1 = Strongly Disagree to $5=$ Strongly Agree. The questions were directed toward trainees' evaluation of how their behavior and approach to others with diverse perspectives had changed over the year since the training. Examples of the questions include: "I have a clearer perspective on why valuing and appreciating diversity is important for my organization and why I need to monitor my behavior" and "I have been able to modify my behavior when I believe I am not responding appropriately to persons I perceive to be different from me." Cronbach alpha reliability for this scale was .85. Participants were again asked to complete Diversity Intention statements with the wording of the one-year follow-up intention statements changed from future to present and past tense to reflect a level of success in participating or carrying out diversity-related actions following the training (for example, "I will join and actively work in a local organization dealing with discrimination" was changed to "Joined and actively worked in a local organization dealing with discrimination"). Participants rated themselves on a five-point scale of $1=$ Made No Attempt to $5=$ Generally Succeeded. Finally, the thirty-three-item DEQ was again completed. Cronbach alpha reliability for the DSE and Diversity Intention were .96 and .77 , respectively. 


\section{Results}

The means, standard deviations, and inter-correlations of study variables are presented in Table 2.

Preliminary Analyses on Control Variables. Prior to testing hypotheses, we examined control variables within the sample. ANOVAs determined that there were no significant differences between training and control groups in terms of age $[F(1,271)=1.75$, ns $]$; total work experience $[F(1,264=2.54$, ns $)]$; gender $[F(1,270=1.76, n s)]$; organization $[F(1,274)=1.54, n s]$; and race $[F(1$, $248)=1.80$, ns]. Also, 80 percent of the participants reported no prior diversity training.

Manipulation and Randomization Checks. One-way ANOVA results showed no significant difference in pretraining diversity self-efficacy scores between the training group and the one-time DSE measure for the control group $[F(1,250)=.515, p<.520, \mathrm{~ns}]$. However, the experimental training intervention did have a positive impact on DSE perceptions, as expected. Paired samples t-test showed that postmeasures of DSE increased significantly over premeasures for the training group [ $t(162) 10.10, p<.001]$. Means and standard deviations for pre- and post-DSE scores are: pre $(\mathrm{M}=2,212$, $\mathrm{SD}=537.56)$ and post $(\mathrm{M}=2,515, \mathrm{SD}=514.65)$. In addition, the analysis of variance between the training group and control on posttraining measures of DSE was significant and is reflected in Table 3. The mean for the training group $(M=2,497.95, S D=531.69)$ was significantly higher than the mean of the control $(\mathrm{M}=2,261.12, \mathrm{SD}=619.80)$.

Test of Hypotheses. Although directly assessing the highly sensitive, specific performance behaviors and outcomes associated with DSE was not permitted to be measured, the effect of DSE perceptions on confidential diversity performance intentions and the self-reported impact a year later were examined. Table 2 displays results of the correlation of pre- and postdiversity self-efficacy (DSE) measures, intention difficulty (INTDIF), and number of intentions selected (INTSEL). As shown, hypothesis 1 was supported. Higher diversity self-efficacy perceptions positively relate with the difficulty and number of specific action intentions selected to promote a highly desirable diversity climate. The results were a positive, significant relationship between DSE, with both intention difficulty and number of intentions selected on both the pre- and posttraining data.

Results also indicate partial support for hypothesis 2. This hypothesis stated that training participants would experience increased posttraining intentions in terms of level of difficulty and quantity of their intentions to promote a positive diversity climate back on the job. A paired sample $t$-test of pre- and postmeasures of intention difficulty for the training group was significant, $t(170)=4.20, p<.001$ (Pre $\mathrm{M}=7.42, \mathrm{SD}=3.07$; Post $\mathrm{M}=8.32$, SD $=3.73$ ). Likewise the number of intentions selected posttraining was signifi- 


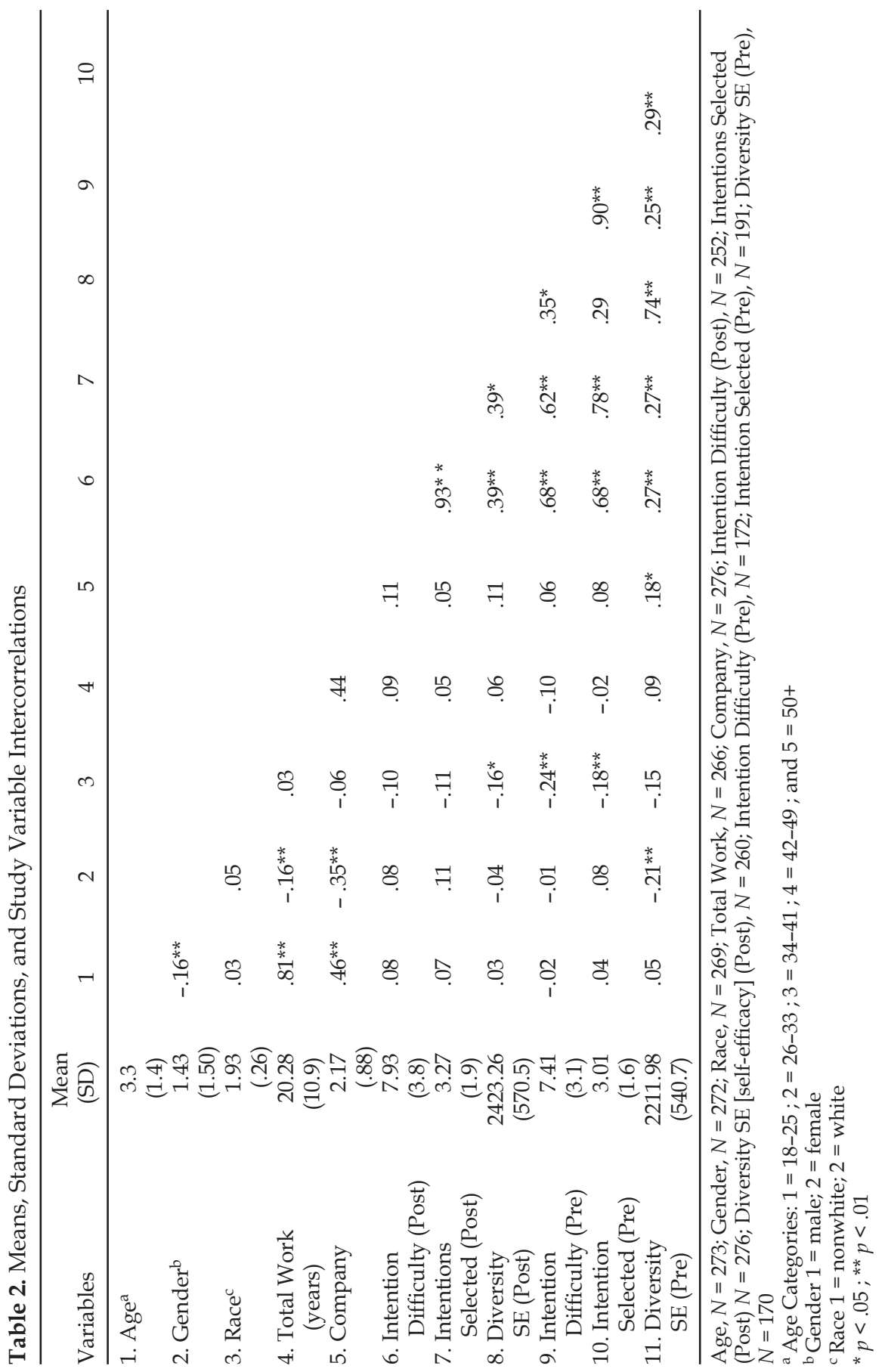


Table 3. Results of One-Way ANOVA for Training and Control Groups on Postdiversity Self-Efficacy Scores

\begin{tabular}{lrrrrr}
\hline Source & $d f$ & \multicolumn{1}{c}{ SS } & \multicolumn{1}{c}{ MS } & $F$ & $\eta^{2}$ \\
\hline Intervention & 1 & $3,148,652.4$ & $1,611,989.7$ & $10.01^{* *}$ & .037 \\
Error & 258 & $81,153,439.3$ & $314,548.2$ & & \\
\hline
\end{tabular}

$N=260 .{ }^{* *} \mathrm{p}<001$.

cantly higher than the premeasure, $t(189)=4.73, p<.0001$ (Pre $\mathrm{M}=3.03, \mathrm{SD}$ $=1.56$; Post $\mathrm{M}=3.43$; $\mathrm{SD}=1.98)$. Comparison was also made of the training group to the control group through one-way ANOVA. The result was a significant difference between the training group and control for number of intentions selected $[F(1,274)=4.6, p<.05]$. Intention difficulty was nonsignificant $[F(1,250)=2.1, p<.145, \mathrm{~ns}]$; however, examination of the means show that the training group mean was higher than that of the control group (Training $\mathrm{M}=8.2, \mathrm{SD}=3.8$; Control $\mathrm{M}=7.4, \mathrm{SD}=3.6$ ).

To test hypothesis 3 (whether DSE mediates the relationship between diversity training and diversity intentions), we conducted a regression analyses based on Baron and Kenny's model (1986) for testing mediation. To show full mediation, a series of regressions must be initiated. Specifically there must be (1) a significant relationship between the independent variable and the criterion variable, (2) a significant relationship between the independent variable and the mediator, (3) a significant relationship between the mediator and the criterion variable, and (4) the relationship between the independent variable and the criterion variable is reduced to nonsignificance when the mediating variable is entered into the regression equation.

Following Baron and Kenny's (1986) approach, we can see from Table 4 that DSE fully mediated the relationship between training and number of diversity intentions selected. Moreover, the positive impact of diversity training on the number of diversity intentions selected was manifested through the mechanism of diversity efficacy beliefs. As predicted in our hypothesis,

Table 4. Regression Results Showing Mediation Effect of DSE on Relationship Between Diversity Training and Number of Intentions Selected

\begin{tabular}{lccccccc}
\hline Variable Relationship & $\beta$ & $t$ & $R^{2}$ & SE & $F$ & $d f$ & $p$ \\
\hline Training/intentions & .131 & 2.16 & .018 & .238 & 4.66 & 258 & $.032^{*}$ \\
Training/DSE & .380 & 6.51 & .157 & .000 & 46.74 & 258 & $.000^{* *}$ \\
DSE/intentions & .392 & 6.84 & .153 & .000 & 23.90 & 257 & $.000^{* *}$ \\
Training/intentions & .060 & 1.02 & .157 & .225 & 23.90 & 257 & $.307 \mathrm{~ns}$ \\
(controlling for DSE) & & & & & & &
\end{tabular}

All coefficients are standardized.

${ }^{*} p<.01 ;{ }^{* *} p<.001$. 
Table 5. Regression Results Showing Mediation Effect of DSE on the Relationship Between Diversity Training and Intention Difficulty

\begin{tabular}{lccccccc}
\hline Variable Relationship & $\beta$ & $t$ & $R^{2}$ & SE & $F$ & $d f$ & $p$ \\
\hline Training/intentions & .081 & 1.26 & .007 & .511 & 1.58 & 242 & $.209 \mathrm{~ns}$ \\
Training/DSE & .380 & 6.51 & .157 & .000 & 46.74 & 258 & $.000^{* *}$ \\
DSE/intentions & .390 & 6.52 & .155 & .000 & 22.17 & 241 & $.000^{* *}$ \\
Training/difficulty & .022 & .374 & $.155^{\text {a }}$ & .478 & 22.17 & 241 & $.708 \mathrm{~ns}$ \\
(controlling for DSE) & & & & & & & \\
\hline
\end{tabular}

All coefficients are standardized.

${ }^{a}{ }^{2}$ of .155 primarily driven by DSE.

$* * p<.001$.

taking DSE into account removed any effect that training had on the number of intentions selected.

As indicated in Table 5, we again used Baron and Kenny's (1986) model to examine diversity self-efficacy as a mediator of the relationship between diversity training and intention difficulty. The first regression requirement was not met. There was not a significant relationship between training and intention difficulty. However, there were positive significant relationships between training and our proposed mediator DSE and DSE with intention difficulty. In addition, the relationship between training and intention difficulty was nonsignificant when DSE was controlled. Using the more recent Kenny, Kashy, and Bolger (1998) guidelines (they contend that the initial significant relationship between the training and intention difficulty as required in regression 1 under the Baron and Kenny, 1986, approach is not a necessary condition to show full mediation), if the second, third, and fourth regressions are satisfied, then DSE fully mediated the relationship between training and intention difficulty. Therefore, using the Kenny et al. (1998) guidelines, there is full mediation of DSE between training and intention difficulty.

To further test the full mediation of DSE on the training and intention difficulty relationship, we submitted the data to the SOBEL test to detect whether the mediating variable (diversity efficacy) carries the influence of the independent variable (diversity training) to a dependent variable (intention difficulty). The $\mathrm{p}$ values reported in this examination take into account the indirect effect of the independent variable on the dependent variable as a consequence of the mediating variable. In particular, this test demonstrates a two-tailed test of the hypothesis that the mediated effect is zero in the population using \pm 1.96 as critical values, which is 95 percent of the normal distribution. In applying this statistic, we found the indirect effect was significant $(\mathrm{z}-.298, p=.002)$, with the DSE variable significantly mediating the effect of training on the secondary outcome variable of intention difficulty. These analyses provide support for hypothesis 3 . 
Summary of One Year Follow-Up Questionnaire. Although there were no specific hypotheses regarding the follow-up data, analyzing participant perceptions and activities subsequent to the training can add credibility to the posttraining intentions. The results indicated that one year following training, participant DSE continued to have a significant positive correlation with the number of diversity actions pursued $(r=.41, p<.01)$ and the level of difficulty of the actions pursued $(r=.53, p<.01)$. There was a significant difference between the training group and the control group on the difficulty of the actions attempted $[t(83.42)=2.18, p<.032]$. The means and standard deviations for difficulty were: control $\mathrm{M}=17.71, \mathrm{SD}=10.38$ and training group $\mathrm{M}=22.80, \mathrm{SD}=15.03$. The mean for number of intentions selected for the training group was higher than the control but not significant (Training $\mathrm{M}=$ 4.62, $\mathrm{SD}=2.83$; Control $\mathrm{M}=3.91, \mathrm{SD}=2.40$ ).

In addition, those receiving training indicated a greater frequency of success with carrying out diversity intentions after the training than those in the control group. Success was measured by the percentage of those who indicated responses ranging from 3 to $5(3=$ made some attempt; $5=$ generally succeeded) on the revised (wording for this follow-up analysis) intention statements. Table 6 shows that on each intention statement, the training group showed a greater percentage of persons selecting 3 or higher. Overall, the percentage differences between the control and training groups for the various intentions ranged from 4.9 percent to 20.5 percent. For those intentions rated as difficult, the training group reported more success (responding with a 4 or 5) than the control group. The percentage of those reporting higher success on difficult intentions $3,5,7$, and 10 were $8,6,5$, and 20 percent, respectively.

Participants' perception of training effectiveness a year later was measured using seven items. The seven questions that assessed participants' perception of training effectiveness showed a positive significant correlation with DSE $(r=.53, p<.01)$. As participants' diversity self-efficacy in-

Table 6. Percentage of Subjects Experiencing Success on Diversity Intentions One Year Following the Training by Training and Control Groups

\begin{tabular}{lrrrrrrrrrr}
\hline Intentions $^{\mathrm{a}}$ & 1 & 2 & 3 & 4 & 5 & 6 & 7 & 8 & 9 & 10 \\
\hline Control (\%) $^{\mathrm{b}}$ & 23.5 & 2.9 & 79.4 & 55.9 & 2.9 & 11.8 & 47.1 & 11 & 5.9 & 23.5 \\
Training (\%) $^{\mathrm{c}}$ & 35.7 & 12.2 & 87.8 & 68.4 & 9.1 & 20.3 & 52 & 20.4 & 11.3 & 44.0 \\
\% Difference $^{\mathrm{d}}$ & 12.2 & 9.3 & 8.4 & 12.5 & 6.2 & 8.5 & 4.9 & 9.4 & 5.4 & 20.5 \\
\hline
\end{tabular}

a Intention statements in questionnaire.

${ }^{b}$ The percentage of those in the control group who indicated success with an intention.

${ }^{c}$ The percentage of those in the training group who indicated success with an intention.

${ }^{d}$ Reflects the greater percentage of those in the training group who experienced success than those in the control group. 
creased, so did their perception of personal change one year following training. Training and control groups differed on their perceptions of the change in their perspective and actions regarding promoting desirable diversity initiatives subsequent to training. On average, 25 percent of the training group and 18 percent of the control group strongly agreed (the highest rating for the scale) that their perspective on the need to value diversity and monitor personal behaviors toward diverse others had been positively influenced. Fifty-two percent of the training group and a considerably lower 44 percent of controls rated themselves as 4 or 5. Examined separately, the training group scored higher on six of the seven questions, with virtually no difference on one. Between training and control groups, the training group showed the greater difference in knowing the importance of valuing diversity (17 percent difference); behaving at work so that their actions are examples for others (6 percent difference); identifying appropriate behaviors that promote diversity (16 percent difference); identifying derogatory comments related to race, gender, age, and disability status (8 percent difference); and understanding the problems caused by lack of acceptance of diverse others (18 percent difference).

\section{Discussion}

This study addresses some of the effectiveness and transfer problems associated with diversity training. We suggest that diversity training that focuses on the development of domain-specific diversity self-efficacy will enhance trainees' intentions that facilitate promoting and sustaining a positive organizational climate for diversity.

A major finding of the study was that diversity training emphasizing self-efficacy components drawn from Bandura $(1997,2000)$ led to significant increases in trainees' measured DSE. Positioning diversity training effectiveness within the context of the established self-efficacy-performance relationship (Eden \& Zuk, 1995; Schwoerer et al., 2005; Stajkovic \& Luthans, 1998a) begins to delineate specific trainee factors that may affect diversity training outcomes. The importance of DSE in the effectiveness of diversity training and meeting diversity training goals was empirically supported by the finding that trainees' level of self-efficacy is significantly related to the level of difficulty and number of intentions to engage in positive diversity actions and initiatives.

Furthermore, the study findings showed a significant difference between pre- and postmeasures of intention difficulty and number of intentions selected, as well as significantly higher means on these two measures for those receiving diversity efficacy training versus a control group that received no training. These findings suggest that diversity training designed to incorporate the sources of self-efficacy can have a positive effect on intentions to engage in positive diversity actions. HRD professionals and researchers recognize that effective interactions in a diverse environment can be challenging and sensitive 
(Holladay et al., 2001; Wentling \& Palma-Rivas, 2000). The need for efficacy and confidence may sustain not only the diversity effort but also the individual when confronted with sometimes unpleasant circumstances in the workplace. Organizations seeking to promote employee and client diversity may be able to develop human capital through efficacy-based diversity training.

This study suggests that perceptions of DSE are positively and significantly related to engagement in diversity-related intentions and may be a precursor of actual performance. In other words, experimental results, plus the sustainability found in the one-year follow-up data, provide at least beginning evidence that diversity training that emphasizes self-efficacy can be effective and have a positive impact on intentions to engage in initiatives that foster a positive diversity climate. Hom et al. (2000) provide evidence that intentions to act precede and do serve as reasonable predictors of sensitive behaviors that usually cannot be directly measured. Also, organizational research through the years (George \& Jones, 1996; Kirshenbaum \& Weisberg, 2002; Lee \& Mitchell, 1994; Steers \& Mowday, 1981) effectively uses intentions as substitutes for actual behavior. The training and organizational behavior literatures are clear in their recognition of the importance of self-efficacy on intentions in several domains (Betz \& Voyten, 1997; Waller, 2006; Zhao et al., 2005). Thus, our results are in line with perceptions about the utility of self-efficacy. This study also provides a new perspective to diversity training by recognizing the need to build DSE in participants.

Finally, this study suggests that DSE may mediate the influence of diversity training on participants' intentions to promote a positive diversity climate and attain diversity initiatives back on the job. This relationship, which has been presented by Mager (1992), may be a critical link for the transfer of diversity training and effective diversity management. Mediation analysis controlling for diversity self-efficacy rendered the previous significant differences of the training intervention on intention difficulty and number of intentions to nonsignificance. This supports the mediating role of diversity selfefficacy on intentions to carry out positive diversity-related behaviors. HRD professionals seeking to determine pre- and posttraining transfer factors may benefit by specifically analyzing how trainee cognitive factors influence diversity training outcomes. Important here is identification of the mechanism during training that may control or mitigate the effects of subjective norms on trainee readiness and motivation to learn in the diversity training.

The follow-up data that were collected one year following the field experiment lend sustainability support to the experimental hypotheses and credibility to the intentions measure. These data provide evidence that those in the training group attempted more difficult intentions and indicated a greater frequency of success in carrying out diversity-related intentions. In addition, those receiving training reported greater positive differences in their perceptions of the importance of valuing diversity and monitoring their actions regarding promoting diversity on the job. However, these follow-up data are not intended to substantiate a direct causal effect and are not offered as a 
substitute for objective behavioral observation of diversity behaviors of the participants back on the job. Yet the descriptive analysis of the participant perceptions does suggest support for the stated intentions to promote and accomplish a positive diversity climate in the nontraining environment. Although only aggregate reporting of the data was possible due to initial confidentiality provisions of the original data collection, on balance it appears that enhanced levels of diversity self-efficacy seem to mediate the influence of diversity training on the promotion and attainment of a workplace climate that positively supports diversity.

The developed DEQ contains specific actions, skills, and behaviors found in the literature and by an expert panel to be important for demonstrating effective appreciation and successful management of diversity. The factor analysis supported one component accounting for 51 and 40 percent of variance of posttraining and a separate student sample, respectively. Although social desirability bias may be a problem for those taking the DEQ, Fisher and Katz (2000) have noted that there are situations where it is not appropriate to control for or attempt to reduce social desirability bias. They suggest that if a concept or construct is associated with a widely held societal value, then controlling for social desirability bias would constitute an error in measurement. Following this argument, the DEQ may be such an instrument, influenced by societal values related to interpersonal interactions and organizational competitive advantages through diversity understanding and appreciation. The historical and contemporary context of diversity and responses to it may have had the effect of establishing a societal values component to valuing diversity. Thus, it could be argued that social desirability bias, if present, is an expected and appropriate aspect of the DEQ. Our research did not seek to resolve this issue in conjunction with the development of the DEQ. However, this interesting question suggests an area for future research.

Study Limitations. Limitations of this study are found in the reality of doing any field research but may be compounded by the sensitive nature of the diversity topic (Bell, 2006). For example, participating organizations indicated a genuine desire to commit to the diversity training activity, but because of the sensitive and potential legal nature of the data, we were not able to directly measure behaviors back on the job. Also, the six-hour duration of the training may have limited the effect of the training. A longer time span may be required for self-efficacy to sufficiently mediate the relationship between diversity training and level of difficulty of intention to promote a positive diversity work climate. However, this time frame is typical of what we see in organizational training schedules. Furthermore, the racial/ethnic homogeneity of the sample prohibited an examination of cross-cultural interactions and opportunity to assess differences in efficacy perceptions across different racial and ethnic groups. Finally, the data were obtained through trainee self-report of their self-efficacy perceptions. This could suggest a social desirability effect on the measures of intentions and levels of self efficacy. 
However, as Peterson (2006, p. 7) has recently pointed out, "Social desirability is hardly a nuisance variable when one studies what is socially desirable."

Future Research. Future extension of research examining diversity training incorporating self-efficacy components would benefit from the inclusion of objective, non-self-report indexes of change in diversity management effectiveness subsequent to training. This would permit the examination of a more causal model of diversity training effectiveness. Although our one-year follow-up information provides some insights on sustainability and impact, a true assessment of the influence of training on behaviors back on the job would use longitudinal research to provide some objective data on the transfer of training.

Although we do not have a measure of organizational context (for example, environmental conditions or perceptions of the work environment) in this study, we do recognize that such measures should be included in future research. The assessment of organizational context can contribute to the better understanding of diversity training outcomes and diversity behaviors of employees. For example, a substantial factor in employee choice behavior and selfregulatory processes related to effective response to diversity situations may come from normative factors of organizational leadership and the support and reinforcement of positive diversity behaviors. Often the anecdotal perception of employees is that organizational climate reflects mere lip-service to maximizing the positive forces of a diverse workforce. Future research would benefit from an examination of the influence of contextual forces (for example, organizational climate, management support) on diversity initiatives.

Although the analysis of race effects did not show significant influence on DSE or intention measures, inspection of group means showed that nonwhites actually had higher postdiversity self-efficacy measures than whites. Future research to examine these differences may provide insights into the impact of diversity training on perceived diversity self-efficacy across racial lines.

Implications for HRD. This study finds that diversity training that focuses on the self-efficacy components (enactive mastery, modeling, verbal and social persuasion, and psychological arousal) has a positive relationship with trainee intentions to engage in positive diversity initiatives. In addition, the diversity training to intention relationship was shown to be mediated by trainee diversity self-efficacy. These findings are important to HRD professionals in several ways. First, the results inform research and practice concerning diversity training design. By identifying DSE as an important consideration in diversity training and underscoring its relationship to diversity intentions, the study encourages HRD researchers to begin to systematically explore diversity training effectiveness in terms of trainees' psychological characteristics. From this study, we learn that such trainee characteristics as self-efficacy can be important to the success of diversity training. Diversity training that attends to building self-efficacy about diversity initiatives may contribute to the capability of 
trainees to begin or sustain positive actions that are important to the success of organizational strategies to maximize the benefits of diversity.

Second, organizations are seeking ways to demonstrate the effectiveness of diversity training (Wentling \& Palma-Rivas, 2000). HRD professionals are continually requested to justify the dollar expenditure for employee training and development (Holton et al., 2000). Therefore, methods to influence the return on investment in diversity training address a critical concern for HRD practitioners. Measuring DSE as an integral step in diversity training and assessing its impact on trainee actions after training may assist in answering the return-on-investment concern. Study results regarding intentions and the one-year follow-up information provide direction for positioning diversity training in the realm of successful diversity initiatives.

Finally, this study addresses the general goals of development of organizational human resources. Building human capital strengths is a recognized foundational aim of HRD. The influence of diversity self-efficacy on intentions implies that diversity training that takes a developmental approach can possibly strengthen managers' and employees' confidence not only with areas such as gender and race but also in cross-cultural interactions in the new global economy. Organizations with diverse domestic and international workforces could maximize the benefits of diversity that lead to increased organizational performance and profitability (Richard, 2000).

\section{Conclusion}

This study contributes to the case that the self-efficacy construct is rich in its capacity to be applied in a breadth of research and application areas. Although needing further research, the DEQ measure shows considerable potential for quantifying diversity self-efficacy and helps in systematically analyzing diversity training effectiveness and performance outcomes. Granted all assessments related to diversity need not rely solely on quantifiable measures and experimental designs, we hope this study is beneficial to diversity-related research in general and, importantly, makes a contribution to the badly needed credibility and value of diversity training.

Since no recognized diversity training effectiveness measures exist, our beginning development of a measure of diversity self-efficacy (DEQ) not only allowed a reliable and initially valid way to measure the confidence and belief of individuals to successfully value and promote diversity initiatives, but also, at least to some extent, gauges the effectiveness of diversity training. We hope that this study helps to move us from mere assumptions and surface analysis to empirically demonstrated diversity training effectiveness. The positive relationship found between diversity self-efficacy beliefs and diversity-related desirable intentions, supplemented by the one-year follow-up data, points to a connection between this new type of diversity training and desirable outcomes for meeting the challenges of a truly pluralistic, positive climate for today's organizations. 


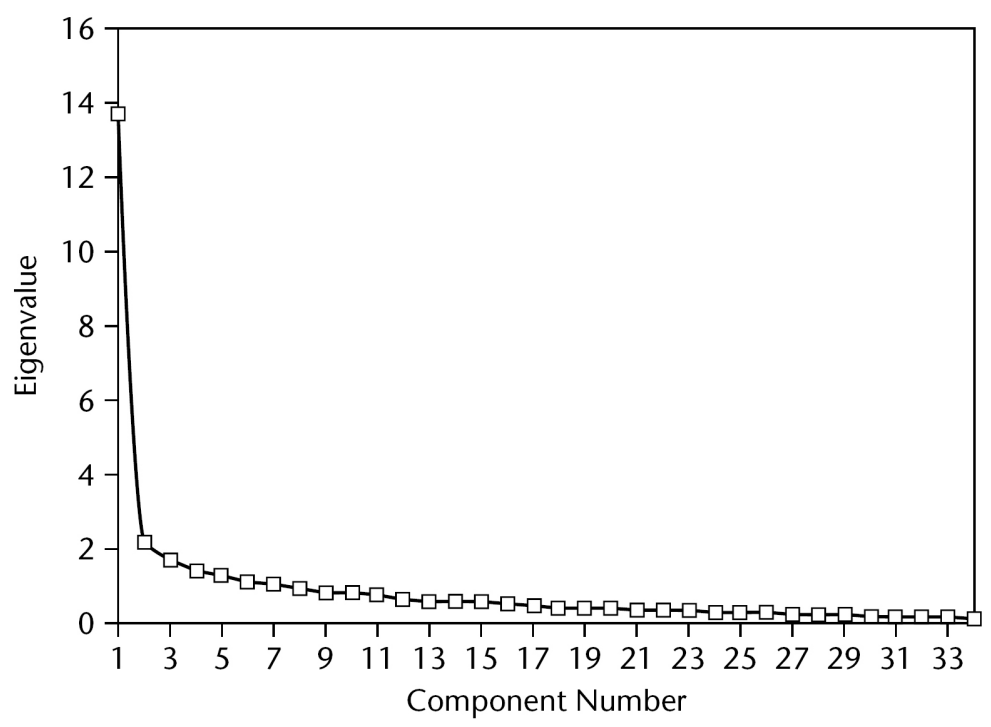

APPENDIX: Figure 1. Scree Plot of Factor Analysis for Student Sample

\section{References}

Bandura, A. (1986). Social foundation of the thought and action. Upper Saddle River, NJ: Prentice Hall.

Bandura, A. (1997). Self-efficacy: The exercise of control. New York: Freeman

Bandura, A. (2000). Cultivate self-efficacy for personal and organizational effectiveness. In E. Locke (Ed.), Handbook of principles of organizational behavior. Malden, MA: Blackwell.

Barbian, J. (2003, February). Moving toward diversity. Training, 45-47.

Barling, J., \& Beattie, R. (1983). Self-efficacy beliefs and sales performance. Journal of Organiza tional Behavior Management, 5, 41-51.

Baron, R. M., \& Kenny, D. A. (1986). The moderator-mediator variable distinction in social psychological research: Conceptual, strategic, and statistical considerations. Journal of Personality and Social Psychology, 51, 1173-1182.

Baytos, L. M. (1995). Designing and implementing successful diversity programs. Upper Saddle River, NJ: Prentice Hall.

Bell, M. (2006). Managing diversity in organizations. Mason, $\mathrm{OH}$ : Thomsen South-Western.

Betz, N. E., \& Luzzo, D. A. (1996). Career assessment and the career decision making self efficacy scale. Journal of Career Assessment, 4, 313-328.

Betz, N., \& Voyten, K. K. (1997). Efficacy and outcome expectations influence on career exploration. Career Development Quarterly, 46, 197-189.

Brief, A. P., Buttram, R. T., Reizenstein, R. M., Pugh, S. D., Callahan, J. D., McCline, R. L., \& Vaslow, J. B. (2002). Beyond good intentions. In P. J. Frost, W. R. Nord, \& L. A. Krefting (Eds.), HRM reality: Putting competence in context (pp. 187-200). Upper Saddle River, NJ: Prentice Hall.

Bucher, R. D. (2000). Diversity consciousness opening our minds to people, cultures, and opportunities. Upper Saddle River, NJ: Prentice Hall. 
Budner, S. (1962). Intolerance of ambiguity as a personality variable. Journal of Personality. 30, 29-50.

Chen, C. C., \& Hooijberg, R. (2000). Ambiguity intolerance and support for valuing-diversity interventions. Journal of Applied Social Psychology, 30, 2392-2408.

Colquitt, J. A., LePine, J. A., \& Noe, R. A. (2000). Toward an integrative theory of training motivation: A meta-analytic path analysis of 20 years of research. Journal of Applied Psychology, 85, 678-707.

Combs, G. M., \& Nadkarni, S. (2005). A tale of two cultures: Attitudes towards affirmative action in the United States and India. Journal of World Business, 40, 158-171.

Combs, G. M., Nadkarni, S., \& Combs, M. W. (2005). Implementing affirmative action plans in multinational corporations. Organizational Dynamics, 34, 346-360.

Connerley, M. L., \& Pedersen, P. B. (2005). Leadership in a diverse and multicultural environment. Thousand Oaks, CA: Sage.

Cox, T. H. (2000). Creating the multicultural organization: A strategy for capturing the power of diversity. San Francisco: Jossey-Bass.

Cox, T. H., \& Beale, R. (1997). Developing multicultural competence: Readings, cases and activities. San Francisco: Berrett-Koehler.

Cox, T. H., \& Nkomo, S. M. (1991). A race and gender group analysis of early career experiences of MBA's. Work and Occupations, 18, 431-446.

Dass, P., \& Parker, B. (1996). Diversity a strategic issue. In E. E. Kossek \& S. A. Lobel (Eds.), Managing diversity human resource strategies for transforming the workplace. Malden, MA: Blackwell.

Davidson, M. N. (1999). The value of being included: An examination of diversity change initiatives in organizations. Performance Improvement Quarterly, 12, 164-180.

De Meuse, K. P., \& Hostager, T. J. (2001). Developing an instrument for measuring attitude toward and perceptions of workplace diversity: An initial report. Human Resource Development Quarterly, 12, 33-51.

Eden, D., \& Aviram, A. (1993). Self-efficacy training to speed re-employment: Helping people to help themselves. Journal of Applied Psychology, 78, 352-360.

Eden, D., \& Zuk, Y. (1995). Seasickness as a self-fulfilling prophecy: Raising self-efficacy to boost performance at sea. Journal of Applied Psychology, 80, 628-635.

Fisher, R. J., \& Katz, J. E. (2000). Social desirability bias and the validity of self-report values. Psychology and Marketing, 17, 105-120.

Ford, J. K., \& Weissbein, D. A. (1997). Transfer of training: An updated review and analysis. Performance Improvement Quarterly, 10(2), 22-41.

Galvin, T. (2003, October). The Twenty-Second Annual Industry Report. Training, 19-45.

George, J. M., \& Jones, G. R. (1996). The experience of work and turnover intentions: Effects of value attainment, job satisfaction, and positive mood. Journal of Applied Psychology, 81, 318-325.

Gist, M. E. (1989). The influence of training method on self-efficacy and idea generation among managers. Personnel Psychology, 42, 787-805.

Gist, M. E., Schwoerer, C., \& Rosen, B. (1989). Effects of alternative training methods on self-efficacy and performance in computer software training. Journal of Applied Psychology, 78, 884-891.

Gist, M. E., Stevens, C. K., \& Bavetta, A. G. (1991). Effects of self-efficacy and posttraining intervention on the acquisition and maintenance of complex interpersonal skills. Personal Psychology, 44, 837-861.

Goldstein, I. L., \& Ford, J. (2002). Training in organizations (4th ed.). Belmont, CA: Thomsen. 
Gorsuch, R. L. (1974). Factor analysis. Philadelphia: Saunders.

Hanover, M. B., \& Cellar, D. F. (1998). Environmental factors and the effectiveness of workforce diversity training. Human Resource Development Quarterly, 9, 105-124.

Haq, R. (2004). International perspectives on workplace diversity. In M. S. Stockdale \& S. Crosby (Eds.), The psychology and management of workplace diversity. Malden, MA: Blackwell.

Hemphill, H., \& Haines, R. (1997). Discrimination, harassment and the failure of diversity training-What to do now. Westport, CT: Quorum Books.

Holladay, C. L., Knight, J. L., Paige, D. L., \& Quiñones, M. A. (2003). The influence of framing on attitudes toward diversity training. Human Resource Development Quarterly, 14, 245-263.

Holton, E. F., III, Bates, R. A., \& Ruona, W.E.A. (2000). Development of a generalized learning transfer system inventory. Human Resource Development Quarterly, 11, 333-360.

Hom, P. M., Griffeth, R. W., \& Gaertner, S. (2000). A meta-analysis of antecedents and correlates of employee turnover: Update, moderator tests, and research implications for the next millennium. Journal of Management, 26, 463-488.

Ivancevich, J. M., \& Gilbert, J. A. (2000). Diversity management. Public Personnel Management, 29, 75-92.

Kanter, R. M. (2004). Confidence. New York: Crown.

Kenny, D. A., Kashy, D. A., \& Bolger, N. (1998). Data analysis in social psychology, In D. Gilbert, S. Fiske, \& G. Lindzey (Eds.), The handbook of social psychology (4th ed., Vol. 1, pp. 233-265). New York: McGraw-Hill.

Keppel, G. (1991). Design and analysis: A researcher's handbook. Upper Saddle River, NJ: Prentice Hall.

Kidder, D. L., Lankau, D., Chrobot-Mason, D., Mollica, K. A., \& Friedman, R. A. (2005). Backlash towards diversity initiatives: Examining the impact of diversity program justification, personal and group outcomes. International Journal of Conflict Management, 15, 77-102.

Kirshenbaum, A., \& Weisberg, J. (2002). Employee's turnover intentions and job destination choices. Journal of Organizational Behavior, 23, 109-126.

Kravitz, D. A., \& Klineberg, S. L. (2000). Reactions to two versions of affirmative action among whites, blacks, and Hispanics. Journal of Applied Psychology, 85, 597-611.

Lee, C., \& Bobko, P. (1994). Self-efficacy beliefs: Comparison of five measures. Journal of Applied Psychology, 79, 364-369.

Lee, T. W., \& Mitchell, T. R. (1994). An alternative approach: The unfolding model of voluntary employee turnover. Academy of Management Review, 19, 51-89.

Luthans, F. (2002a). The need for and meaning of positive organizational behavior. Journal of Organizational Behavior, 23, 695-706.

Luthans, F. (2002b). Positive organizational behavior: Developing and managing psychological strengths. Academy of Management Executive, 16, 57-72.

Machin, M. A., \& Fogarty, G. (2003). Perceptions of training related factors and personal variables as predictors of transfer implementation intentions. Journal of Business and Psychology, 18, 51-71.

Maddux, J. E. (2002). Self-efficacy: The power of believing you can. In C. R. Snyder \& S. Lopez (Eds.), Handbook of positive psychology (pp. 257-276). New York: Oxford University.

Mager, R. (1992, April). No self-efficacy, no performance. Training, 32-36. 
Manstead, S. R., \& van Ekelen, S.A.M. (1998). Distinguishing between perceived behavioral control and self-efficacy in the domain of academic achievement intentions and behaviors. Journal of Applied Social Psychology, 28, 1375-1392.

O'Connor, P. (1952). Ethnocentrism, "intolerance of ambiguity," and abstract reasoning ability. Journal of Abnormal and Social Psychology, 47, 526-530.

Peterson, C. (2006). A primer in positive psychology. New York: Oxford University Press.

Plantenga, D. (2004). Gender, identity, and diversity: Learning from insights gained in transformative gender training. Gender and Development, 12, 40-46.

Richard, O. C. (2000). Racial diversity, business strategy, and firm performance: A resource-based view. Academy of Management Journal, 43, 164-177.

Richard, O. C., \& Johnson, N. B. (1999). Making the connection between formal human resource diversity practices and organizational effectiveness: Behind management fashion. Performance Improvement Quarterly, 12, 77-96.

Roberson, L., \& Block, C, J. (2001). Racioethnicity and job performance: A review and critique of theoretical perspectives on the causes of group differences. Research in Organizational Behavior, 23, 245-325,

Roberson, L., Kulik, C. T., \& Pepper, M. B. (2003). Using needs assessment to resolve controversies in diversity training design. Group and Organization Management, $28,148-174$.

Rodgers, W. M., \& Brawley, L. R. (1996). The influence of outcome expectancy and self-efficacy on the behavioral intentions of novice exercisers. Journal of Applied Social Psychology, 26, 618-634.

Rosenthal, R., \& Rosnow, R. L. (1991). Essentials of behavioral research methods and data analysis. New York: McGraw-Hill.

Schwoerer, C. E., May, D. R., Hollensbe, E. C., \& Mencl, J. (2005). General and specific self-efficacy in the context of a training intervention to enhance performance expectancy. Human Resource Development Quarterly, 16, 111-129.

Sherer, M., Maddux, J. E., Mercandante, B., Prentice-Dunn, S., Jacobs, B., \& Rodgers, R. (1982). The self-efficacy scale: Construction and validation. Psychological Reports, 51, 663-671.

Smith-Jentsch, K. A., Salas, E., \& Brannick, M. T. (2001). To transfer or not to transfer? Investigating the combined effects of trainee characteristics, team leader support, and team climate. Journal of Applied Psychology, 86, 279-292.

Stajkovic, A. D., \& Luthans, F. (1998a). Self-efficacy and work-related performance: A metaanalysis. Psychological Bulletin, 24, 240-261.

Stajkovic, A. D., \& Luthans, F. (1998b). Social cognitive theory and self-efficacy: Going beyond traditional motivational and behavioral approaches. Organizational Dynamics, 26, 62-74.

Steers, R. M., \& Mowday, R. T. (1981). Employee turnover and post decision accommodation processes. In L. Cummings \& B. Staw (Eds.), Research in organizational behavior. Greenwich, CT: JAI Press.

Stockdale, M. S., \& Cao, F. (2004). Looking back and heading forward: Major themes of the psychology and management of workplace diversity. In M. S. Stockdale \& S. Crosby (Eds.), The psychology and management of workplace diversity. Malden, MA: Blackwell.

Thomas, D. A., \& Proudford, K. L. (2000). Making sense of race relations in organizations: Theories for practice. In R. T. Carter (Ed.), Addressing cultural issues in organizations: Beyond the corporate context. Thousand Oaks, CA: Sage. 
Tracey, W. R., Tannenbum, S. I., \& Kavanagh, M. J. (1995). Applying trained skills on the job: The importance of the work environment. Journal of Applied Psychology, 80, 239-252.

Tsui, A. S., \& Gutek, B. A. (1999). Demographic differences in organizations: Current research and future directions. Lanham, MD: Lexington Books.

Waller, B. (2006). Math interest and choice intentions of nontraditional African American students. Journal of Vocational Behavior, 68, 538-547.

Watson, D., Clark, L. A., \& Tellegen, A. (1988). Development and validation of brief measures of positive and negative affect: The PANAS scales. Journal of Personality and Social Psychology, 54, 1063-1070.

Wentling, R. M., \& Palma-Rivas, N. (1998). Current status and trends of diversity initiatives in the workplace. Human Resources Development Quarterly, 9, 235-253.

Wentling, R. M., \& Palma-Rivas, N. (2000). Current status of diversity initiatives in selected multinational corporations. Human Resources Development Quarterly, 11, 35-60.

Wiethoff, C. (2004). Motivation to learn and diversity training: Application of the theory of planned behavior. Human Resource Development Quarterly, 15, 263-278.

Williams, S., and Shiaw, W. T. (1999). Mood and organizational citizenship behavior: The effects of positive affect on employee organizational citizenship behavior intentions. Journal of Psychology, 133, 656-669.

Wood, R. E., \& Bandura, A. (1989). Social cognitive theory of organizational management. Academy of Management Review, 14, 361-384.

Zhao, H., Seibert, S. E., \& Hills, G. E. (2005). The mediating role of self-efficacy in the development of entrepreneurial intentions. Journal of Applied Psychology, 90, $1265-1272$.

Zimmerman, B. J., \& Bandura, A. (1994). Impact of self-regulatory influences on writing course attainment. American Educational Research Journal, 36, 845-862.

Gwendolyn M. Combs is an assistant professor in the Department of Management at the University of Nebraska-Lincoln.

Fred Luthans is George Holmes Professor, Department of Management, at the University of Nebraska-Lincoln. 